\title{
The Relationship between Age and Happiness Varies by Income
}

\author{
Dimiter Toshkov ${ }^{1}$ \\ Institute of Public Administration, Leiden University, the Netherlands
}

This version: 10 March 2021

An extended and revised version of this manuscript was published on 31 August 2021 by the Journal of Happiness Studies.

The open-access text of the article is available at: https://doi.org/10.1007/s10902-021-00445-7 Additional data visualizations and $\mathrm{R}$ code are available at: http://dimiter.eu/Happiness2021.html

\begin{abstract}
The link between age and happiness has been the subject of numerous studies. It is still a matter of controversy whether the relationship is U-shaped, with happiness declining after youth before bouncing back in old age, or not. While the effect of age has been examined conditional on income and other socio-demographic variables, so far, the interactions between age and income have remained insufficiently explored. Using data from the European Social Survey, this article shows that the nature of the relationship between age and happiness varies strongly with different levels of relative income. People in the lowest decile of the income distribution experience a 'hockey stick': a deep decline in self-reported happiness until around age 50-55 and a small bounce back in old age. The classic Ucurve is found mostly in the middle-income ranks. For people at the top of the income distribution, average happiness does not vary much with age. These results demonstrate the important role of income in moderating the relationship between age and happiness.
\end{abstract}

\section{Keywords}

age, happiness, income, interaction effects, well-being

${ }^{1}$ Corresponding author: d.d.toshkov@,fgga.leidenuniv.nl ORCID: 0000-0002-7444-9340. No specific funding is acknowledged. The author is not aware of any conflicts of interest with regard to this research. The data and code for this article are available at: [to be completed upon publication]. 


\section{Introduction}

How does happiness vary with age? What is the effect of income on happiness? These are central questions in the study of subjective well-being that have received a lot of attention from different social-scientific disciplines (Blanchflower and Oswald 2004; Galambos et al. 2020; Frijters and Beatton 2012; Yang 2008) and have captured the public interest as well (Rauch 2018). The major contribution of this article is to show that the effects of age and income need to be considered together, because they interact, so that the effect of age differs at different levels of income, and the effect of income differs in different age groups.

Analyzing the effect of age in the context of specific income categories puts in new light the controversy about the nature of the relationship between age and happiness. Several seminal studies have argued that age is related in a $\mathrm{U}$-curve pattern to happiness: happiness declines from youth to middle age and then bounces back in old age (Blanchflower and Oswald 2004; 2008; Gerdtham and Johannesson 2001). There is plenty of empirical evidence that has been marshaled in favor of this interpretation (most recently, Blanchflower 2021). At the same time, important critiques have been raised against the U-curve as well, arguing that the empirical evidence is weaker than it appears (Galambos et al. 2020) and that the U-curve appears only after inappropriate adjustments to the data have been made (Glenn 2009; Bartram 2020). While the variations in the shape of the relationship between age and happiness across different countries and time periods have been explored (Bittmann 2020), how the relationship changes for people with different incomes is a question that has not received a lot of scientific attention (Hsieh 2011). But, as it turns out, the relationship differs significantly for people at the bottom, in the middle, and at the top of the income ladder, going from a 'hockey stick' - a deep and almost linear decline with a small bounce back in old age - to the classic U-curve to a flat line for the very rich.

There is much broader agreement about the effect of income on happiness (Blanchflower and Oswald 2004; Hsieh 2011; Gerdtham and Johannesson 2001; van Praag, Frijters, and Ferrer-iCarbonell 2003). However, one unresolved issue is the form of the relationship: whether happiness increases linearly with income, or money has diminishing returns after a point reached already with middle incomes. Analyzing the interactive effects of age and income in affecting subjective well-being sheds new light on this issue as well. As the analyses show, the effect of (relative) income is linear for the young, but it departs from linearity for people in mid-age and, especially so, for the old, among which the effect is almost flat above the middle-income categories. 
The arguments about the interactive effects of age and income that this article advances are tested on data from the European Social Survey (Wave 9, 2018). The large number of respondents included in the survey (close to 50,000) allows the main effects of age and income and their interaction to be studied semi-parametrically, without strongly imposing functional forms on their relationships with happiness. The article reports the results of a number of general additive models (gam) that estimate the effects and introduces two- and three-dimensional plots that visualize the complex interactions of age and income. In addition, I explore how these relationships differ across the 29 European countries included in the ESS Wave 9, and I trace how they have changed over the past 16 years looking at the previous 8 waves of the ESS survey.

To examine what accounts for the varying effects of age at different income levels, I show that the effects of many strong predictors of happiness, such as health, marital status, religiosity and others, vary significantly with income. As a result, once the influence of these predictors is taken into account, the effect of age on the residual values of happiness does not vary so strongly with income anymore. A U-curve is found for all income levels, net of the effects of health and other socio-demographic predictors.

The implications of these results are quite broad. The evidence presented in this article suggests that rich people manage to avoid the mid-life dip in happiness. They do that, partly, by being less susceptible to the negative effects of poor health or remaining single. This suggests that by addressing these problems one can help bridge the gap in average happiness between people at the bottom and at the top of the income distribution, which, as the data presented here shows, is greatest in late middle age.

\section{Age, income and happiness: theoretical considerations}

Despite the numerous empirical studies of the relationship between age and subjective well-being ${ }^{2}$, there is no consensus about form of the relationship (Blanchflower and Oswald 2004; 2008; Glenn 2009; Laaksonen 2018; Frijters and Beatton 2012; Bartram 2020; Gerdtham and Johannesson 2001; Fukuda 2013) ${ }^{3}$. In a series of articles, Blanchflower and Oswald forcefully argue that the link is U-

\footnotetext{
2 The concept of subjective well-being is broader than the concept of happiness on which the empirical part of this paper is focused. To make sure that the results generalize beyond this one measure of subjective well-being, in the Supplementary Materials I report replication of the main results using an alternative variable that measures the same concept - life satisfaction.

${ }^{3}$ For a literature review, see (López Ulloa, Møller, and Sousa-Poza 2013) and the extended discussion in (Galambos et al. 2020).
} 
shaped, and that the U-shape can be found for humans around the world (Blanchflower and Oswald 2008; 2004; 2009; Blanchflower 2021) and even among the great apes (Weiss et al. 2012). Others, however, have challenged both the robustness and the generality of the U-curve (Bartram 2020; Galambos et al. 2020; Kassenboehmer and Haisken-DeNew 2012) ${ }^{4}$. The disagreements partly boil down to the question whether the effect of age should be estimated net of other (typically, sociodemographic) variables or not (Blanchflower and Oswald 2009; Glenn 2009). If we are interested in the total effect of age (Bittmann 2020), the answer is 'no', because these socio-demographical are likely mediators rather than confounders of age (Bartram 2020), as they cannot cause age (for a dissenting opinion, see Bezimeni 2011). If we are interested only in the direct effect of age that is not exercised via the influence of health, education, occupation, marital status, and so on, then indeed we should filter out the influence of these variables to see how age affects the residual variation in happiness.

Clearly, both approaches are useful but they answer different questions. While the relationship between unadjusted age and subjective well-being is informative about what people can expect about their average happiness as they grow old, the effect of age net of covariates is informative about the mechanisms though which age affects subjective well-being.

It turns out that the U-curve is easier to find once other predictors of happiness have been taken into account (Blanchflower and Oswald 2009; Kassenboehmer and Haisken-DeNew 2012; Bartram 2020; Laaksonen 2018; Frijters and Beatton 2012; Bittmann 2020). This implies that the decline in happiness until mid-age is not entirely due to deteriorating health, unfavorable life events, such as divorce or death of a partner. But there is little commonly-accepted theory about why the Ucurve persists in adjusted data. According to Blanchflower \& Oswald (2008), '[conventional economic theory] does not generate a U-shape in any natural way. Instead, perhaps the most natural conclusion is that well-being might be predicted to be independent of age.' It might be even that some of the reasons for the U-curve are not economic or social, but biological at a level we share with the great apes (Weiss et al. 2012).

To move the understanding of the link between age and subjective well-being further, this article focuses on the interplay between age and income. It is well-known that higher income is associated, on average, with higher happiness (Blanchflower and Oswald 2004; Hsieh 2011; Gerdtham and Johannesson 2001; van Praag, Frijters, and Ferrer-i-Carbonell 2003). In theoretical terms, it can

\footnotetext{
${ }^{4}$ One prominent study of the US finds an increase in happiness over the life course ('With age comes happiness'), once period and cohort effects and other factors are taken in the account (Yang 2008).
} 
be hypothesized that income (and money more generally) should moderate the effect of age. Money can soften the blows of sickness and can partly compensate for lack of social support in old age. As these factors are more likely to become important as one gets old, an interaction between income and age will occur. When a person is young, subjective well-being is less dependent on what money can provide. But in middle age, what brings about happiness and life satisfaction is more likely to require income, even when it comes to getting married, having children and remaining in good health (cf. Hsieh 2011). In old age, theoretically at least, money should still play a big role for subjective wellbeing, because of the need for medical and social support as well ${ }^{5}$.

Moreover, income provides not only material benefits and services that can increase happiness directly or dampen the effect of other factors; it also signals the position of the person in the social hierarchy, which can influence subjective well-being in its own right. The importance of relative income (Tsui 2014; Lee and Ohtake 2021), as an indicator of social status, is likely to be greatest in middle age, when (a) people are still concerned about how they compare to their peers, unlike when they are old and (b) income is a very important metric, unlike when they are young. Yang reviews evidence that older adults are happier because they compare themselves to the less advantaged or because they have a smaller gap between aspirations and achievements (Yang 2008). Note, however, that this implies that old people in the lowest income category should not experience higher average happiness then their young counterparts, because they don't have a category to look and compare down to. Easterlin (2001) develops an economic theory about how the impact of income may vary with age, in which a discrepancy between current and projected aspirations leads to a situation in which even when actual income grows, it fails to generate additional happiness.

These ideas provide sufficient justification for hypothesizing interaction effects between age and income. The effect of income is expected to be strongest in middle age and decline in size both for young and for old people.

If we observe evidence in favor of these theoretical expectations, it will still be necessary to examine the mechanisms through which they work. This calls for testing (a) whether the effects of the important predictors of subjective well-being vary with income, and, if they do, (b) whether taking these effects into account reduces or eliminates the dependencies of the effect of age on income and of the effect of income on age.

\footnotetext{
5 Yang reports that the effects of sex, race and education decrease with age, which contradicts a model in which these variables have cumulative negative effects (Yang 2008).
} 
We can expect the complex relationships between age, income, and other socio-demographic variables to hold in cross-sectional data, even if they are often phrased in terms of effects incurred over one's life course. But the existence of time and cohort effects might complicate finding the relationships in (repeated) cross-sectional data, and their interpretation. Moreover, scholars have argued for significant heterogeneity in the responsiveness of people's subjective well-being in different countries to the effects of age and income (Laaksonen 2018; Bittmann 2020; Hayo and Seifert 2003). For example, inequality, as one measure of the national political and economic context, has been shown to be a significant moderator of the effect of income (Alesina, Di Tella, and MacCulloch 2004). This calls for exploring the nature of the relationship between age and income in individual countries as well, even if for the moment we cannot formulate precise hypotheses about how the national context should moderate their effects.

\section{Research design, data and method of analysis}

To explore the possible interactions between age and income in affecting happiness, I use data from the European Social Survey (ESS). The ESS is a comparative survey of public attitudes and opinions that is fielded periodically in a large number of European countries. The survey is designed and implemented according to the highest professional standards, it follows strict quality protocols with regard to the formulation of the survey items and data collection, and achieves a very high response rate. This results in national samples that are representative (after proper weighting) of the country populations. The main analyses are conducted with data from Wave 9 of the ESS (fieldwork in 2018 and 2019) ${ }^{6}$, which covers 29 countries and has a total of 49,519 respondents. The additional analyses use data from all previous waves of the survey as well, with the earliest one fielded in 2002 (Wave 1).

The main outcome variable of interest - happiness - is operationalized with the survey question: 'Taking all things together, how happy would you say you are?'. The responses are recorded on a 11points scale between 0 and 10, with 'Extremely unhappy' and 'Extremely happy' anchors at both ends of the scale. Only 209 respondents, or less than $0.5 \%$ of the entire ESS Wave 9 sample, have not provided an answer to this question. This is clearly a measure of self-reported happiness, as subjectively experienced by the respondent. The mean of happiness in the sample is 7.4, the median is 8 and the standard deviation is 1.9 .

\footnotetext{
${ }^{6}$ I use the essurvey package for $\mathrm{R}$ to obtain the data (Cimentada 2019).
} 
Age (minimum $=15$, maximum $=90$, mean=51, median=52, standard deviation=18.6) is calculated in years from the self-reported year of birth. Income is measured with the following question: 'Using this card, please tell me which letter describes your household's total income, after tax and compulsory deductions, from all sources? If you don't know the exact figure, please give an estimate. Use the part of the card that you know best: weekly, monthly or annual income.'There are ten categories to choose from, which have been mapped to the income deciles for each country ${ }^{7}$. As such, the income variable measures the relative place of the respondent in the national income distribution. Since incomes vary across the European countries, the measure cannot be interpreted as a measure of absolute income that is directly comparable across countries. This variable has 9,654 missing values, or around $16 \%$ of the sample. With $8 \%$ of the sample each, income deciles 9 and 10 are slightly underrepresented, while deciles 2 to 5 are slightly overrepresented with $11 \%$ each.

The empirical study reported below uses mostly semi-parametric methods of analysis that can capture the hypothesized non-linearities in the relationships between age, income and happiness. To present the results, the study relies heavily on graphical methods for exploring and visualizing the data. Given the complex interdependencies between the covariates, the study employs two- and threedimensional plots to show how average levels of happiness vary for different combinations of age and income.

\section{Empirical results}

The presentation of the empirical results starts with estimating and plotting the unadjusted effects of age and income decile on happiness. The point estimates and $95 \%$ confidence intervals are estimated with a generalized additive model (GAM) with the smooth term based on a shrinkage version of a cubic spline (Wood 2017). ${ }^{8}$ In the combined dataset, in the absence of any adjustments for other covariates, happiness declines with age (see the left panel of Figure 1). There is a blip of an increase after the age of 80 , but this could be an artefact of the relatively few observations at the extreme end of the scale. In absolute terms, the effect of age is relatively small: there is a bit more than 1 point difference from the maximum to the minimum estimate of average happiness (which is less than one

\footnotetext{
7 According to the ESS documentation, 'The categories in variable HINCTNTA [income] are national and based on deciles of the actual household income range in the given country. These deciles are derived from different sources. The median income is the reference point and the 10 deciles are calculated with the median itself at the top of the fifth decile (category F).' ESS waves 1-3 use a similar classification with 12 categories (https://www.europeansocialsurvey.org/docs/round9/survey/ESS9 appendix a2 e03 0.pdf).

8 These models are implemented in $\mathrm{R}$ using the gam function from the mgcv package (Wood 2015) (also via ggplot2). According to the documentation, the model 'specifies a penalized cubic regression spline which has had its penalty modified to shrink towards zero at high enough smoothing parameters (as the smoothing parameter goes to infinity a normal cubic spline tends to a straight line.'
} 
standard deviation in happiness, which, to remind, is measured between 0 and 10). The unadjusted effect of relative income is positive and greater in size. The effect appears to be non-linear, with a steeper increase from the bottom to the middle deciles than after. ${ }^{9}$ These unadjusted effects are useful only as a reference point, because we are interested in the combined effects of age and income.

\section{Unadjusted effects on happiness}
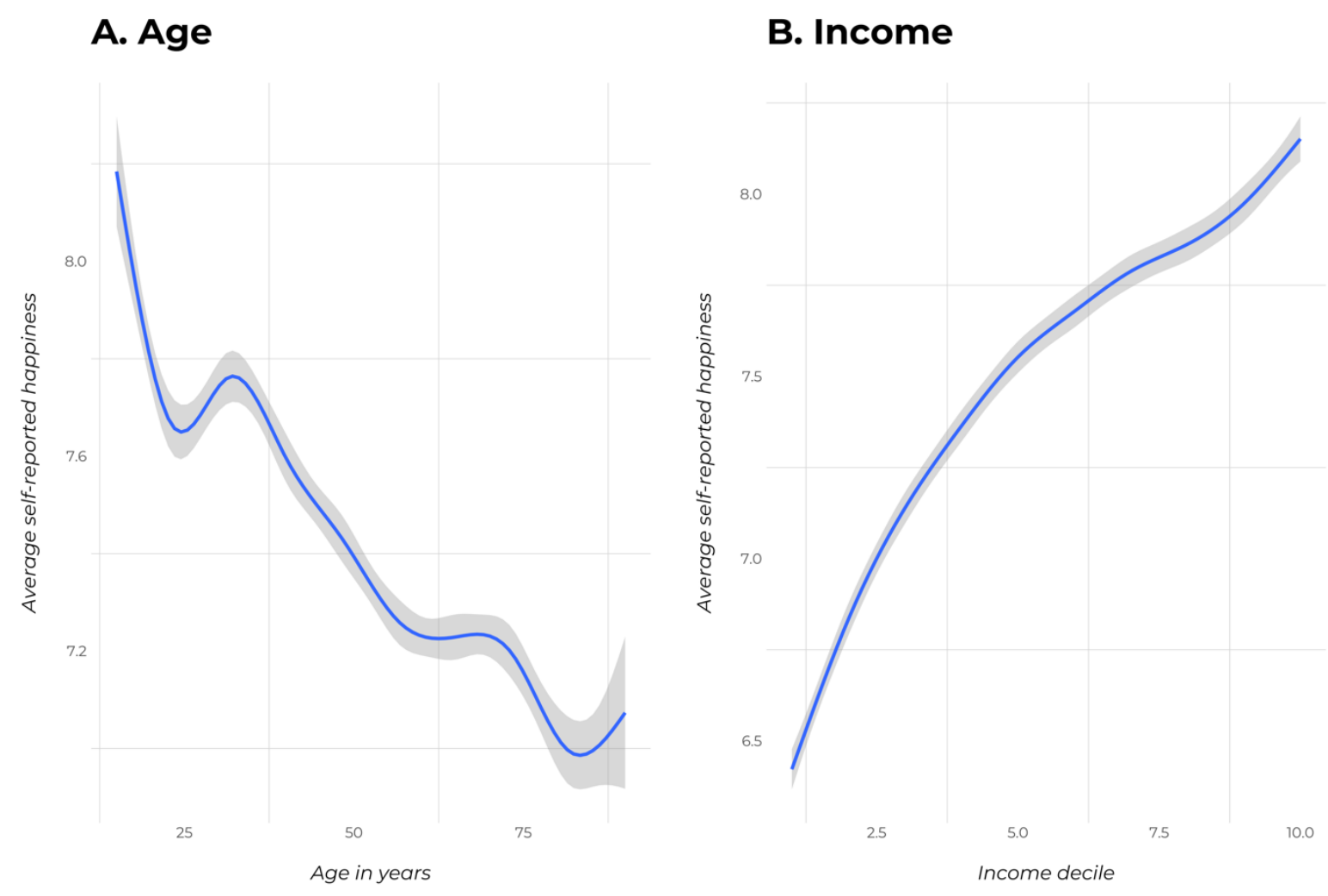

Data: European Social Survey Round 9

Figure 1. Unadjusted effects of age and income on happiness.

To examine the interactive effects, first we plot the effects of age per income decile. Figure 2 shows how the effect of income varies over the observed range of age. The decline of average happiness from youth to middle age is steepest for the poorest people (income decile 1). The decline bottoms at around 50 years and then happiness recovers slightly.

\footnotetext{
9 The relationship between the income categories and absolute income is not linear. In all countries, it takes a smaller amount of absolutely income to move from category 1 to category 2 , then to move from category 4 to 5 , and even less so then needed to move from 9 to 10 . Therefore, when analysed in absolute terms, the effects of income are likely to be even more strongly non-linear than the ones presented here.
} 


\section{Effect of age on happiness for different income deciles}

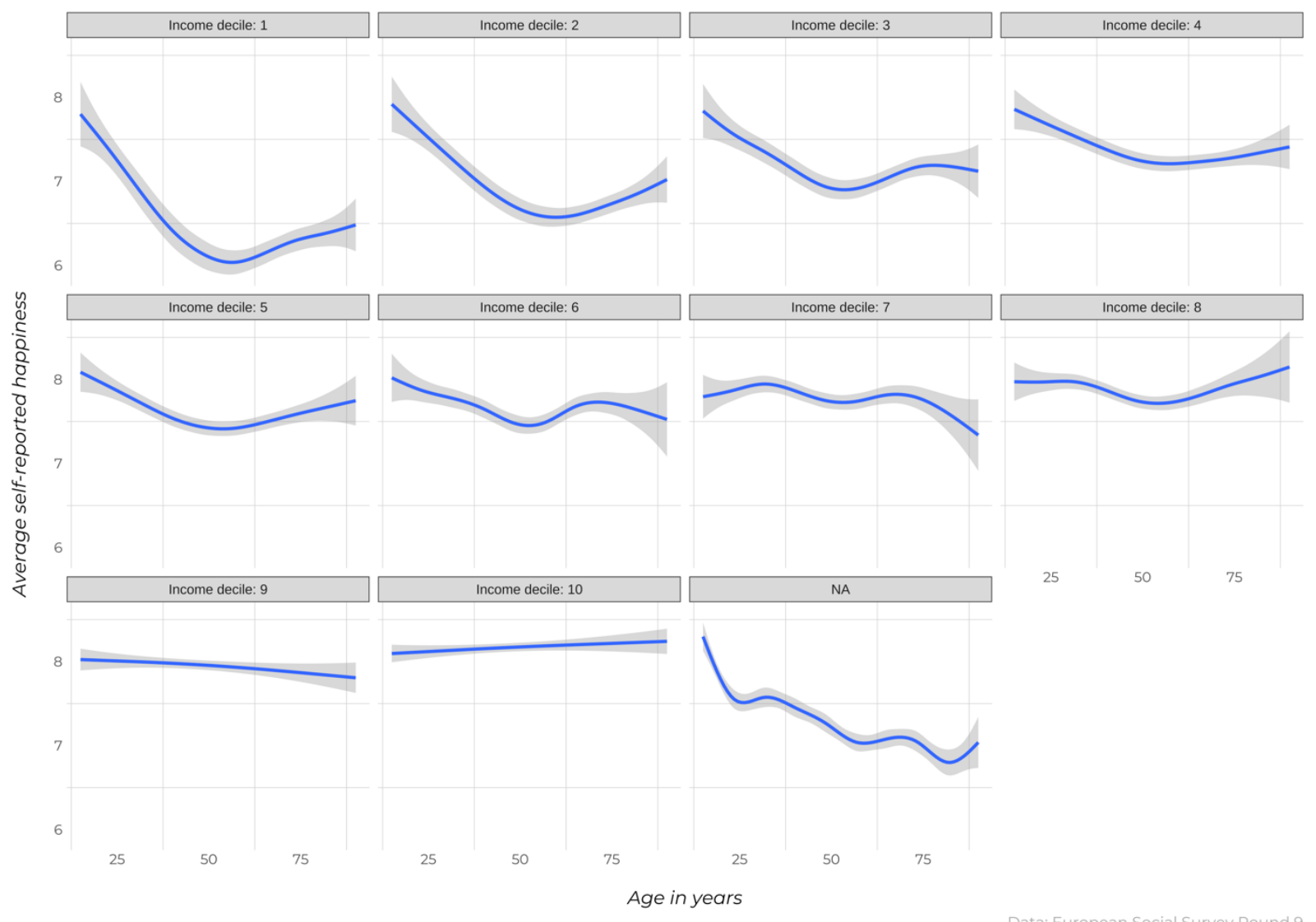

Figure 2. Effect of age on happiness for different income deciles.

As one moves up the income ladder, the dip of happiness with age gets shallower, and the recovery in late middle age gets smaller and more variable as well. From income decile 7 already, there is hardly any decline observable at all, and at income deciles 9 and 10 the effect of age on happiness is practically flat. (The last panel shows the respondents who did not report income, but this is a very mixed group: on average, less educated and younger, but more likely to be studying or unemployed, with low social trust and high feelings for unsafety). Altogether, Figure 2 shows that a U-curve relationship between age and happiness is most clearly visible for poor people, while for people with mid-incomes the relationship flattens out, until it disappears completely for the top two income deciles. 


\section{Effect of income on happiness for different age groups}

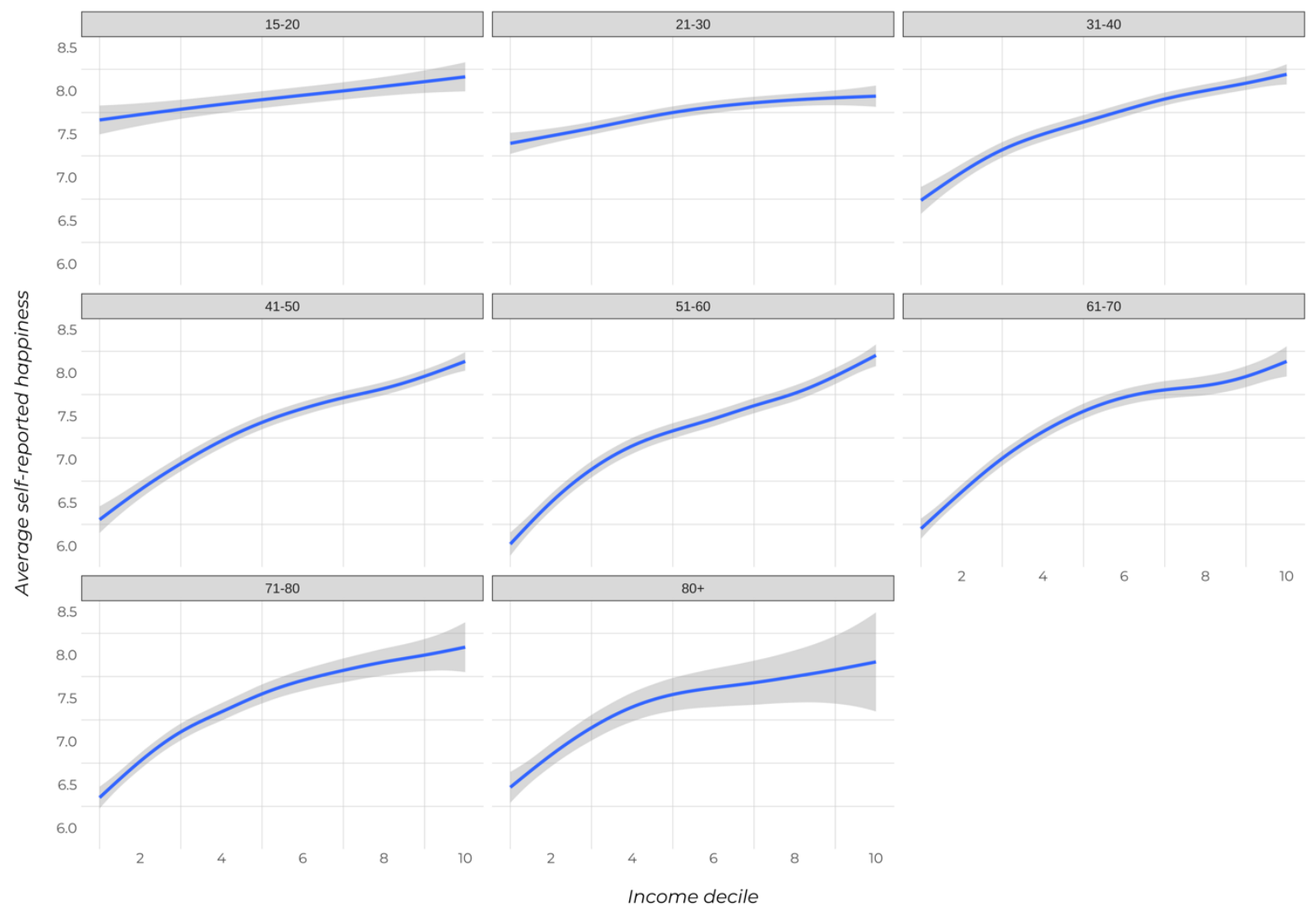

Figure 3. Effect of income on happiness for different age groups.

We can explore the same data by flipping things and looking at the effect of income for different age groups. Again, the effect of income is modeled with the flexible gam function, which does not impose a functional form. As we can see from Figure 3, income is linearly related to happiness for the very young (15-to-20 years), but the positive effect is very small. In the older age groups, however, the effect grows much bigger in size, primarily because people in the bottom deciles of the income distribution have significantly lower happiness than their younger counterparts. The effect is greatest (the slope is steepest) in the 51-60 years group. In the older cohorts the effect of income is markedly non-linear as well. The effect is greater as one moves from the bottom of the income distribution to ranks 4 and 5, but it flattens out considerably after. For old people $(80+$ years), the effect of income after rank 5 is very small. To sum up, income makes the greatest difference for the happiness of people in (late) middle age. For the young, the effect is linear but rather small. For the old, the effect is 
substantial but non-linear: it matters greatly whether you are poor or in the middle of the income distribution, but much less so whether you are in the middle or in the top ranks.

The two figures above provide a clear picture of how the effect of age varies with income and vice versa. But we can also visualize the combined, interactive effects of these two variables simultaneously with two-dimensional (2D) and three dimensional (3D) plots.

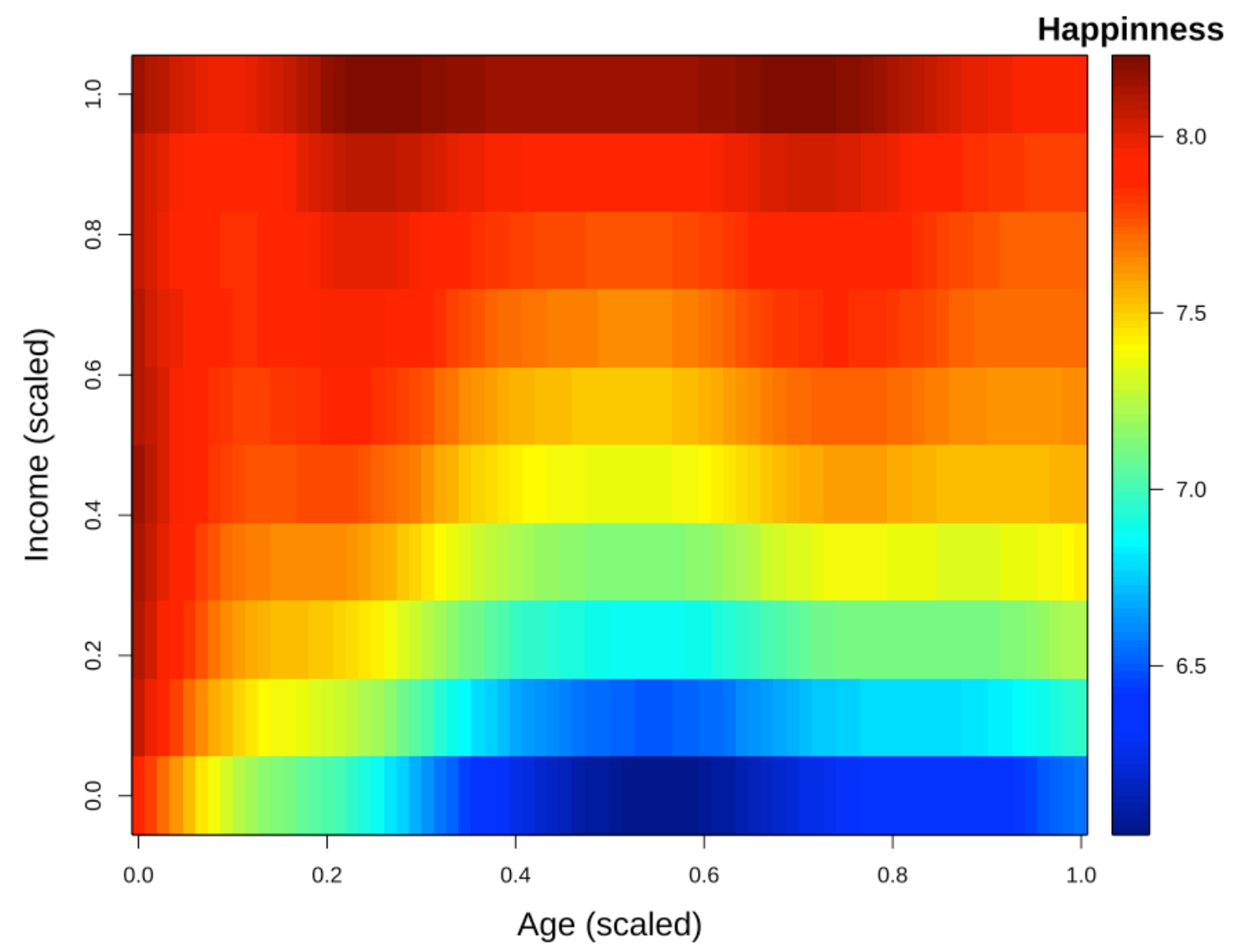

Figure 4. Effect of age and income on happiness: a two-dimensional representation.

In these plots, age and income are mapped to the horizontal dimensions and the average values of happiness are mapped either to color (Figure 4) or to height (Figure 5) ${ }^{10}$. Note that age and income have been scaled between 0 and 1, and the figures focus attention on the relative changes in happiness:

\footnotetext{
${ }^{10}$ For animated and interactive versions of the three-dimensional plots, see: [link to be provided upon publication].
} 
to remind, in absolute terms the variation in average happiness is relatively small, and the effects of age and income, even if significant in the statistical sense, are relatively small in absolute terms.

Figures 4 and 5 suggest that for the top income decile, the effect of age is not only flat, but even peaks in early middle age. They also show that even at the bottom of the middle-age depression, people in the middle income ranks have relatively higher self-reported happiness than poor people older than 25 or so. We can also see how happiness hardly varies with income for the young, but it does so non-linearly for the old. Yet, it is in middle age when, depending on income, one can be either at the highest observed averages of happiness or at the lowest.

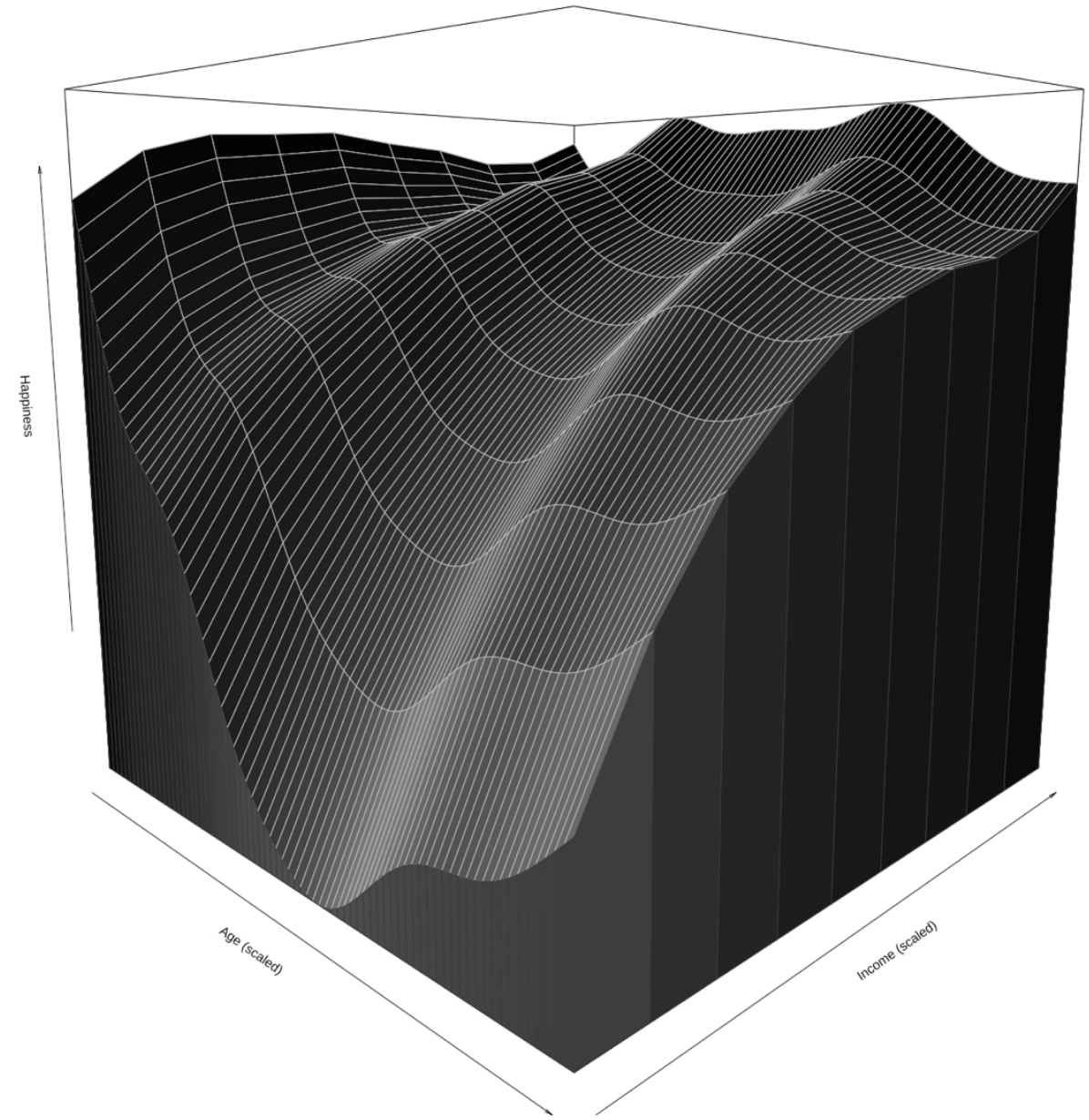

Figure 5. Effect of age and income on happiness: a three-dimensional representation.

The effects that we analyzed so far are based on the entire ESS sample, which features respondents from 29 European countries. But as Figure 6 below shows, there is significant cross-country heterogeneity in the nature of the effects of age and income. Before we discuss the details from the 
figure, however, it should be reminded that the country samples have fewer respondents (between 781 in Cyprus and 2,745 in Italy, with a mean of 1,708), so that some cells in the grid defined by age and income groups can be very sparsely populated. With this disclaimer in mind, we can look at the patterns in different countries in Figure 6, which plots the effect of age for the bottom two deciles (in red) and the top three deciles (in green).

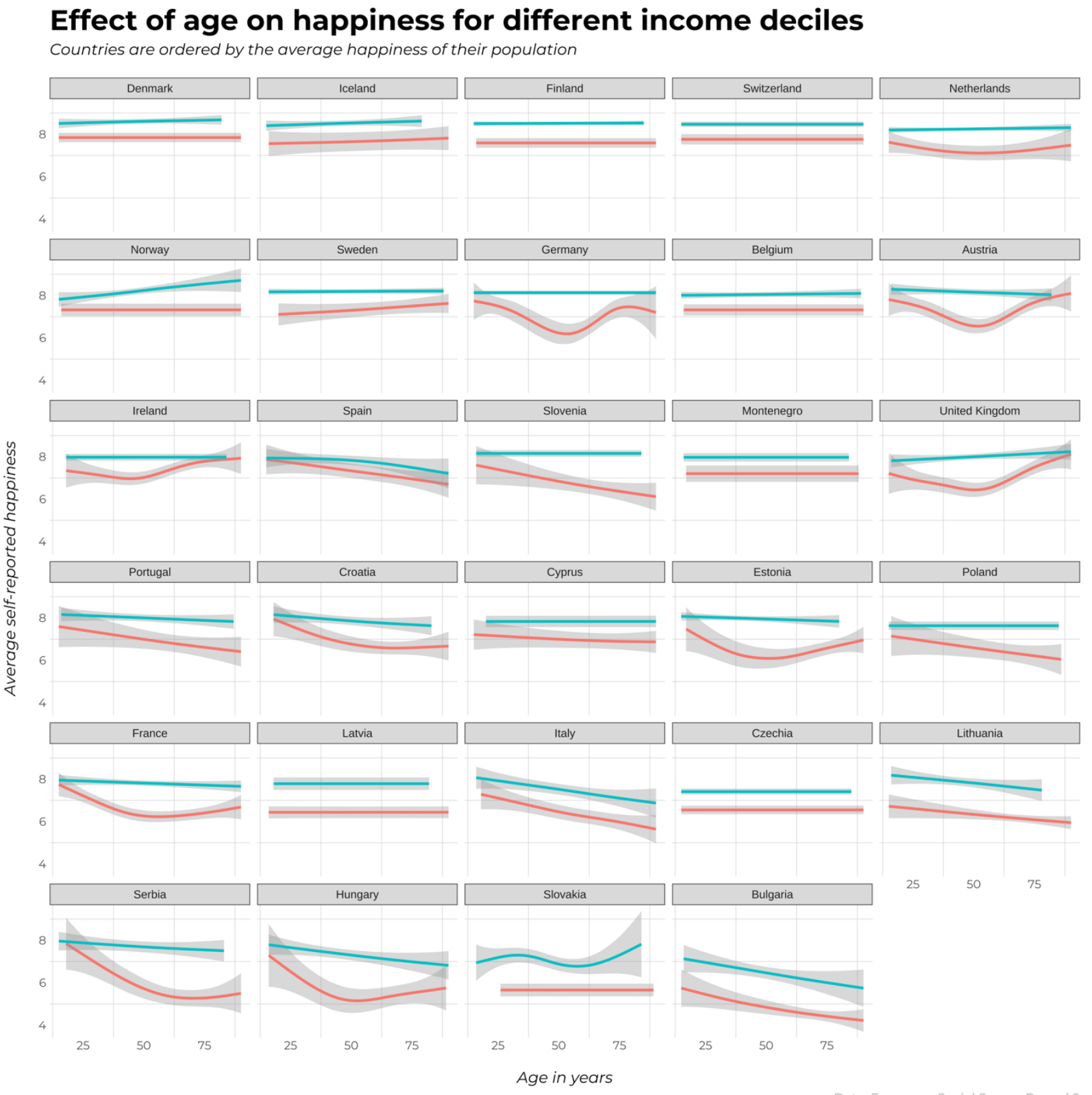

Figure 6. Effect of age on happiness for people at the bottom (income deciles 1 and 2) in red and at the top of the income distribution (income deciles 8 to 10) in green 
While the average happiness of people at the top of the income distribution is invariably higher than that of people at the bottom in all countries, there are important differences. In most European countries, for the rich happiness does not vary much with age. Only in Italy, Hungary, Lithuania and Bulgaria there are significant declines (smaller ones are observed in France, Spain, Serbia and Croatia). In Norway and the United Kingdom, happiness is slightly higher among older people, for the rich.

At the bottom of the income distribution, we find the U-curve relationship between age and happiness in the Netherlands, Germany, Austria, Ireland, the United Kingdom, France, Estonia, Hungary. In a significant number of countries from Southern and Eastern Europe, there is a linear decline of happiness with age for people at the bottom of the income distribution: Spain, Slovenia, Portugal, Croatia, Poland, Italy, Lithuania, Serbia and Bulgaria. In the rest of the countries, happiness does not vary much with age for the poor. These tend to be countries that are wealthy in absolute terms and have strong social safety nets. Finally, note that the gap between rich and poor is greatest in the countries from Eastern Europe. The significant cross-country variation in the patterns reminds us that what we observe in the full ESS sample masks differences into how the effects of age and income, and their interaction, play out in different national contexts. At the same time, only the combined sample provides enough observations to make nuanced observations about the interactive and non-linear effects of age and income with a sufficient degree of confidence.

We can also check whether the patterns we find in 2018 are similar to the ones we can see in the data from the previous waves of the ESS that go back to 2002. As the selection of countries in each wave of the survey is not exactly the same, any differences we find might be partly due to the different country composition of the sample. In addition, the differences might reflect cohort and/or time effects. The ESS is not panel data in which the same respondents are surveyed over time, but repeated cross-sections of nationally-representative samples in a set of partly overlapping countries. Therefore, differences in the apparent effects of age and income across the years might be due to different cohorts having different average happiness and/or common time shocks (e.g. an economic crisis) that affect the average happiness of different age and income groups at the time of the survey differentially.

Figure 7 shows the 2D plots of average happiness as a function of age and income for the period 2002-2018 based on Waves 1-8 of ESS (note that for Waves 1-3 income was originally measured on a 12- rather than a 10-category scale). The overall pattern of interactions remains very similar. At the extreme higher end of the income distribution, the age of peak happiness is somewhat variable from one survey wave to the next, but is most often found in early middle age. 

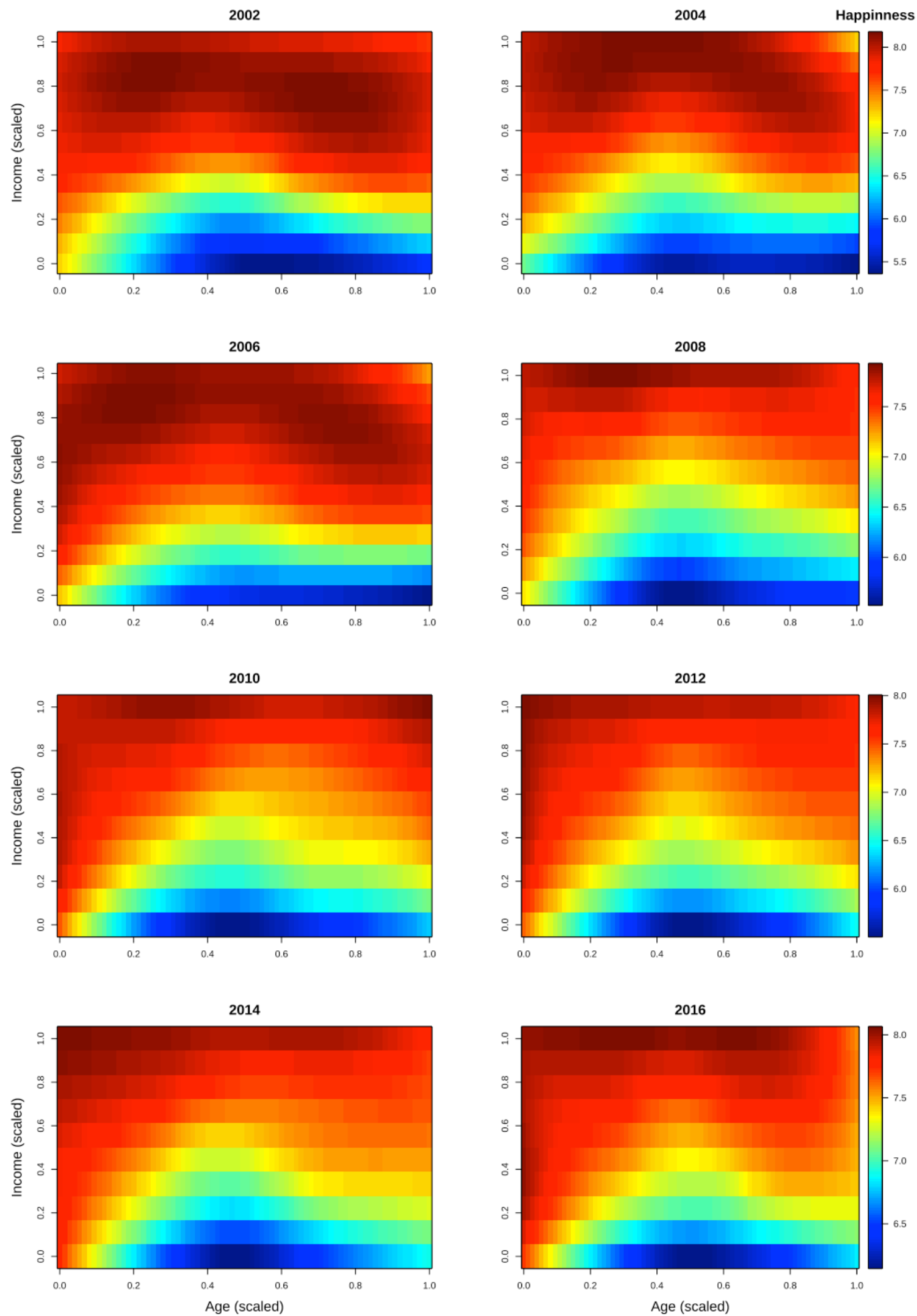

Figure 7. Effects of age and income on happiness over time (2002-2016) 
At the extreme lower end, the lowest values are consistently found in middle age. However, a noticeable improvement for older people comes only after 2008.

What is interesting is that in some years the effect of income for the very old seems not only to level off, but even to decline after the midpoint of the income distribution (2004, 2006). But since even with more than 40,000 respondents per survey wave there are relatively few who reside at the corners of the space defined by age and income, we should not treat this evidence as conclusive.

Overall, people at the lowest three categories of the income distribution express relatively higher levels of happiness over time (see how the blue hues and gradually displayed by green ones in the cells with values between 0 and 0.3 on $y$-axis). However, the middle age decline in happiness seems to run 'deeper' in the higher ranks of the income distribution over time (see how yellow hues displace the red ones in the cells with values between 0.4 and 0.7 on the y-axis).

So far we established that the effect of age on happiness varies across income categories and that the effect of income on happiness has a different form for different age groups. We also showed that these patterns can be found in different time periods, with some minor but important variations. The next question to consider is what accounts for these varying effects. To address this question, in the next part of the analysis I add a set of variables to the models of happiness that can potentially explain why age and income have varying effects. If these variables are indeed related to the mechanisms through which age affects happiness differently for poor and rich people and income affects happiness differently for young, middle-aged, and old people, we would expect that, once their influence is taken into account, the differences in the effects will disappear.

Indeed, we can find evidence that some important predictors of happiness have differential effects $^{11}$ at different income categories. Table 1 shows the results of two statistical models - one multivariate linear regression $(o l s)$ and one generalized additive model $(\mathrm{gam})$ - in which, in addition to age and income, the following variables have been added: gender, education, employment status, religiosity (Lelkes 2006), marital status, number of children, an indicator whether the respondent lives alone, number of children in the household, country indicators (dummies), and subjective health status. These socio-demographic variables are all significant predictors of happiness and altogether capture significant part of the variation in happiness. But we are interested not in their main effects, but whether these effects vary with income. Therefore, we include interactions with income to the model specifications.

\footnotetext{
11 Yang (2008) finds differential effects for race, sex and education, which decrease with age for the US.
} 
Table 1. Models of self-reported happiness

\begin{tabular}{|c|c|c|c|c|c|c|}
\hline \multirow[b]{2}{*}{ Predictors } & \multicolumn{3}{|c|}{ How happy are you? (OLS) } & \multicolumn{3}{|c|}{ How happy are you? (GAM) } \\
\hline & Coef. & SE & $p$ & Coef. & SE & $p$ \\
\hline (Intercept) & 9.57 & 0.17 & $<0.001$ & 8.67 & 0.15 & $<0.001$ \\
\hline Age & -0.04 & 0.00 & $<0.001$ & s(Age) & & $<0.001$ \\
\hline Age squared & 0.00 & 0.00 & $<0.001$ & & & \\
\hline Income decile & 0.05 & 0.03 & 0.06 & 0.05 & 0.03 & 0.06 \\
\hline Feels unhealthy & -0.83 & 0.02 & $<0.001$ & -0.83 & 0.02 & $<0.001$ \\
\hline Gender [male] & -0.15 & 0.04 & $<0.001$ & -0.15 & 0.04 & $<0.001$ \\
\hline Educational category & 0.04 & 0.01 & $<0.001$ & 0.04 & 0.01 & $<0.001$ \\
\hline \multicolumn{7}{|l|}{ Employment [baseline: disabled] } \\
\hline Employment [housework] & 0.24 & 0.12 & 0.05 & 0.23 & 0.12 & 0.06 \\
\hline Employment [other] & -0.13 & 0.19 & 0.50 & -0.13 & 0.19 & 0.50 \\
\hline Employment [paid work] & 0.24 & 0.10 & 0.02 & 0.24 & 0.10 & 0.02 \\
\hline Employment [retired] & 0.39 & 0.10 & $<0.001$ & 0.37 & 0.10 & $<0.001$ \\
\hline Employment [studying] & 0.62 & 0.13 & $<0.001$ & 0.62 & 0.13 & $<0.001$ \\
\hline Employment [unemployed] & -0.05 & 0.12 & 0.68 & -0.04 & 0.12 & 0.73 \\
\hline \multicolumn{7}{|l|}{ Marital status [baseline: single] } \\
\hline Marital status [divorced] & -0.02 & 0.07 & 0.82 & -0.02 & 0.07 & 0.79 \\
\hline Marital status [married] & 0.50 & 0.06 & $<0.001$ & 0.50 & 0.06 & $<0.001$ \\
\hline Marital status [widowed] & -0.09 & 0.08 & 0.28 & -0.08 & 0.08 & 0.30 \\
\hline Lives alone [yes] & -0.14 & 0.05 & 0.01 & -0.15 & 0.05 & 0.01 \\
\hline Has children [yes] & 0.13 & 0.06 & 0.02 & 0.13 & 0.06 & 0.02 \\
\hline Religiosity & 0.08 & 0.01 & $<0.001$ & 0.08 & 0.01 & $<0.001$ \\
\hline \multicolumn{7}{|l|}{ Interactions with income } \\
\hline Income: Feels unhealthy & 0.04 & 0.00 & $<0.001$ & 0.04 & 0.00 & $<0.001$ \\
\hline Income: Male & 0.00 & 0.01 & 0.48 & 0.00 & 0.01 & 0.51 \\
\hline Income: Education & -0.00 & 0.00 & 0.02 & -0.00 & 0.00 & 0.02 \\
\hline Income: Housework & -0.01 & 0.03 & 0.80 & -0.01 & 0.03 & 0.80 \\
\hline
\end{tabular}




\begin{tabular}{|c|c|c|c|c|c|c|}
\hline Income: Other empl. & 0.02 & 0.04 & 0.57 & 0.02 & 0.04 & 0.59 \\
\hline Income: Paid work & -0.02 & 0.02 & 0.42 & -0.02 & 0.02 & 0.41 \\
\hline Income: Retired & -0.03 & 0.02 & 0.14 & -0.04 & 0.02 & 0.12 \\
\hline Income: Studying & -0.07 & 0.03 & 0.01 & -0.07 & 0.03 & 0.01 \\
\hline Income: Unemployed & -0.03 & 0.03 & 0.32 & -0.03 & 0.03 & 0.32 \\
\hline Income: Divorced & -0.00 & 0.01 & 0.97 & 0.00 & 0.01 & 0.97 \\
\hline Income: Married & -0.03 & 0.01 & $<0.001$ & -0.03 & 0.01 & $<0.001$ \\
\hline Income: Widowed & -0.02 & 0.02 & 0.19 & -0.02 & 0.02 & 0.19 \\
\hline Income: Lives alone & 0.01 & 0.01 & 0.24 & 0.01 & 0.01 & 0.24 \\
\hline Income: Has children & 0.01 & 0.01 & 0.57 & 0.01 & 0.01 & 0.54 \\
\hline Income: Religiosity & -0.01 & 0.00 & $<0.001$ & -0.01 & 0.00 & $<0.001$ \\
\hline 28 Country intercepts & & & & & & \\
\hline Observations & \multicolumn{3}{|c|}{38,454} & \multicolumn{3}{|c|}{38,454} \\
\hline $\mathrm{R}^{2} / \mathrm{R}^{2}$ adjusted & \multicolumn{3}{|c|}{$0.257 / 0.255$} & \multicolumn{3}{|c|}{0.255} \\
\hline
\end{tabular}

The difference between the two models is that in the first one age is modeled with linear and quadratic terms, while in the second one its effect is estimated non-parametrically with the cubic splines, as explained above.

According to the results presented in Table 1, religiosity has a significant positive effect on happiness, but the effect is significantly smaller the higher one is in the income distribution: in fact, for the very rich, there is no effect left. As expected, the effect of subjective health is very large: onepoint change on the five-point scale with which subjective health is measured is associated on average with 0.83 change in subjective happiness. But, importantly, this effect declines with income, so that it is half as big for people at the top of the income distribution as it is for people at the bottom. The effect of education is positive, but it declines significantly (if only marginally) with income. In line with this result, the positive effect of being a student (as an occupational category compared to disabled) is smaller for richer people. Similarly, the positive effect of being married declines with position in the income hierarchy. Conversely, the effects of having children (positive) and living alone (negative) do not vary with income. Males report on average lower happiness, but not differentially so by income ${ }^{12}$.

\footnotetext{
12 It is tempting to estimate the interactions of all these predictors of happiness with age as well, but given the non-linear nature of the effect of age itself, the interpretation of such interactions would not be straightforward.
} 
These significant interactions give some idea about the factors that can account for the differential effects of age on happiness in terms of income. Clearly, money can to some extent compensate the negative effect of poor health (that comes with age). Furthermore, generally positive life events such as being a student or getting married are experienced as more positive at the lower ranks of the income distribution. But is this enough to erase the differences in the effect of age at different incomes?

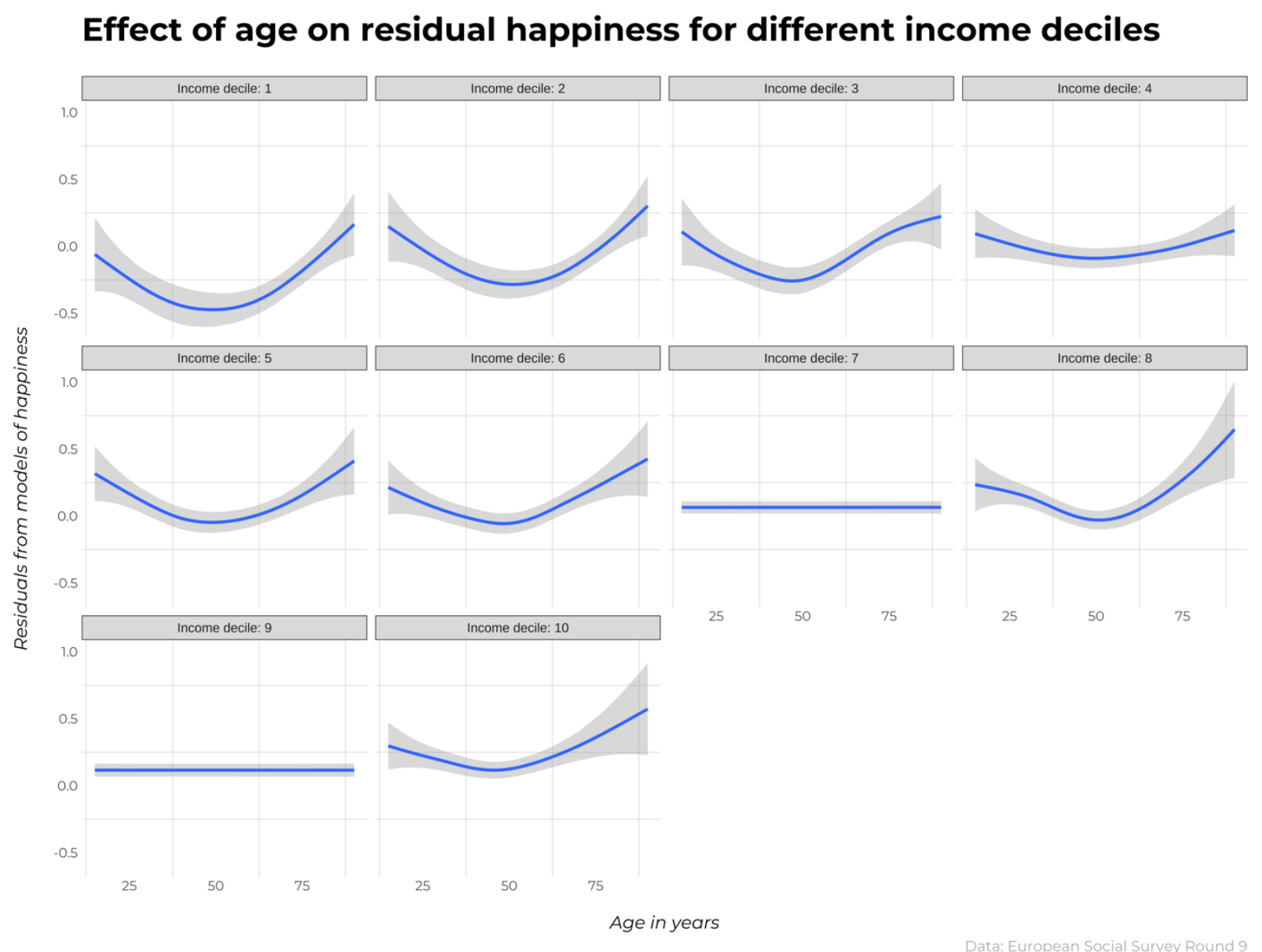

Figure 8. Effect of age on the residuals of happiness, net of socio-demographic predictors

To answer this question, we re-estimate the linear regression model reported in Table 1, but this time without age and income (and its interactions). That is, we use the socio-demographic variables and the country intercepts to predict happiness. Then, we take the residuals from this model, and we use them as the outcome we model as a function of age and income. This results in the same plots as in Figure 2 and Figure 3, but this time instead of 'raw' happiness, the outcome represented on the x-axis is the 
residual variation in happiness that is unexplained by the socio-demographic variables. If these variables account in full for the differential effect of age, we would expect to see that now the effect of age does not differ across income deciles, the effect of income does not differ across age groups and that both effects are linear. As we can see from Figure 8, the effect of age looks more similar in terms of form across the income distribution, even if in terms of level, (residual) happiness is still higher at the top of the distribution. (Income deciles 7 and 9 are exceptions to the U-curve pattern).

\section{Effect of income on residual happiness for different age groups}

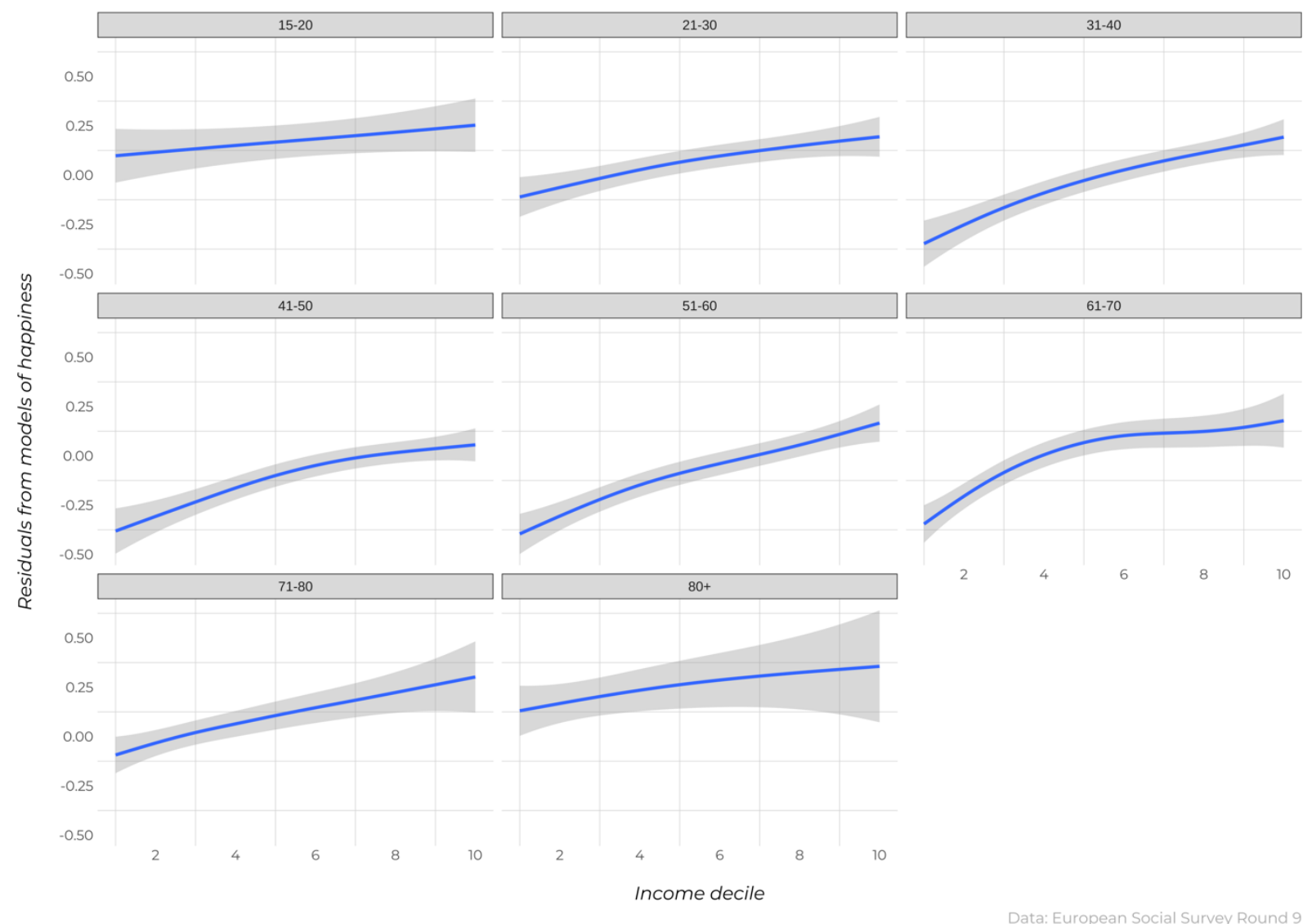

Figure 9. Effect of income on the residuals of happiness, net of socio-demographic predictors

In other words, once the predictors of health have been taken into account, we can find the U-curve across the income distribution. This implies that, conditional on health, education, occupation, marital status, country of residence, and religiosity, people in the middle and at the top of the income distribution also experience a dip in happiness in middle age and a bounce afterwards. In fact, conditional on all these variables, older people who are well-off are even happier than younger people 
in the same income category. While the differences have not completely disappeared, they have been reduced. This implies that part of the reason why richer people do not experience a middle-age dip in happiness is because of better health and favourable social outcomes.

Figure 9 shows the effect of income on the residual happiness per age group. While income still has a positive effect in all age groups, the effect is much small in size. The major difference with the figure that shows the effects on the raw values of happiness is that most of the lines have been 'straightened' (with the exception of the one for group 61-70). This means that the socio-demographic variable account for a large part of the non-linearities in the effect of income, which were most pronounced for older age groups. Hence, conditional on health, marital status, education, and so on, the effect of income does not rise much more rapidly from low to middle income ranks than it does from middle to high income ranks. This implies is that part of the reason why income has a greater effect for moving from the bottom to the middle of the income distribution is because it provides benefits such as health.

\section{Conclusion}

The nature of the relationship between happiness and age is one of the central questions in the literature studying the determinants and predictors of subjective happiness and life satisfaction (Blanchflower and Oswald 2004; 2008; Glenn 2009; Laaksonen 2018; Frijters and Beatton 2012; Bartram 2020; Gerdtham and Johannesson 2001; Fukuda 2013)(Laaksonen 2018)(Laaksonen 2018). Based on survey data for 50,000 Europeans, this article showed that the U-curve is found most clearly for people at the lower ranks of the income distribution and that for people at the higher ranks, happiness does not vary much with age and might even peak in middle age. These patterns differ by country, but remain stable in the European population considered as a whole.

Another important result in the existing literature has been the non-linear nature of the relationship between income and happiness. The evidence presented in this article, however, showed that the non-linearities are stronger for older generations, while in the younger age groups the relationship is almost linear. Importantly, the strength of the impact of income peaks in middle age, when money really seems to make a difference for how happy people feel (or at least how happy they say they are).

In trying to uncover what explains the interactions between age and income and the nonlinearities of their individual effects, I conclude that many socio-demographic predictors of happiness have effects that vary per income. This can account for a significant portion of the different effects of 
age per income: once health, education, marital status and other variables are controlled for, the Ucurve is found at all income levels. Moreover, the effects of income become more linear. These results imply that income makes a difference for happiness by dampening the negative effects of poor health and unfavorable life events. Theoretically, if poor health would have the same effects for poor people as it does for rich, some of the middle-life dip in happiness might disappear. This is because we do not observe the U-curve for rich people in the raw data, but we do once we control for (subjective) health status.

More research into the mechanisms behind the effects of age and income is needed, because not all differential effects and non-linearities disappear with the socio-demographic controls I consider. It could be that some of the mechanisms are related to how people position themselves against others and where they perceive themselves to be in the social hierarchy, compared to where their peers are and where they think they deserve to be. In other words, it is the relative positions in the income and - more generally - social hierarchy that also matter for subjective happiness, and these are of course impossible to erase.

One major limitation of this study is that it is based on cross-sectional data. This means that we cannot interpret the differences across age and income as changes accumulated over a person's lifetime. Essentially, what we observe are differences in happiness for people in different age groups and income levels at the moment of the survey, but we do not know for certain whether these differences are equivalent to changes one experiences over time: getting older, richer or poorer (cf. Yang 2008). A panel design which tracks the same people over a long period of time would be better able to ascertain that the effects I find in this article pertain not only to differences across age groups and income categories, but to life histories as well. For the moment, panel surveys with a long timespan and sufficient number of observations to capture the non-linear, interactive effects explored here are not available. That being said, finding the same patterns in 9 different surveys fielded over a period of 16 years provides some reassurance that they are systematic enough to be worth further study.

Another important limitation is that this study looks at relative rather than absolute income (Tsui 2014; Lee and Ohtake 2021). While relative income is interesting in its own right, replicating the study with an absolute measure of income might lead to different insights about the role of money for happiness. But eliciting precise and valid estimates of the absolute income of people is difficult with standard surveys. This is especially true when it comes to the very rich (the top $1 \%$ of the income distribution) and the super-rich (top $0.1 \%$ ). The dynamic of happiness over the life course might be 
very different for that category of people, and the patterns we find for the top $10 \%$ might not hold at that level.

In methodological terms, this article demonstrated the advantage of semi-parametric methods for the analysis of non-linear and interactive effects, instead of imposing linear, quadratic or other simple functional forms on the data. The application of these methods is nowadays made easy by the availability of powerful, open-source tools, such as the mgcv package (Wood 2015) for the statistical and programming language $\mathrm{R}$, for estimating non- and semi-parametric models and visualizing the results. There seem to be few reasons to resort to parametric forms of analysis when there is sufficient data on which to estimate the non-parametric models in a setting, such as the study of happiness, where the effects of interest are variable and interact with each other in a complex way.

\section{References}

Alesina, Alberto, Rafael Di Tella, and Robert MacCulloch. 2004. "Inequality and Happiness: Are Europeans and Americans Different?” Journal of Public Economics 88 (9): 2009-42.

Bartram, David. 2020. “Age and Life Satisfaction: Getting Control Variables under Control.” Sociology, June, 0038038520926871.

Bezimeni, Uchen. 2011. "Determinants of Age in Europe: A Pooled Multilevel Nested Hierarchical Time-Series Cross-Sectional Model.” European Political Science 10 (1): 86-91.

Bittmann, Felix. 2020. "Beyond the U-Shape: Mapping the Functional Form Between Age and Life Satisfaction for 81 Countries Utilizing a Cluster Procedure.” Journal of Happiness Studies.

Blanchflower, David G. 2021. "Is Happiness U-Shaped Everywhere? Age and Subjective Well-Being in 145 Countries." Journal of Population Economics 34 (2): 575-624.

Blanchflower, David G, and Andrew J Oswald. 2004. "Well-Being over Time in Britain and the USA." Journal of Public Economics 88 (7): 1359-86.

- 2008. “Is Well-Being U-Shaped over the Life Cycle?” Social Science \& Medicine 66 (8): 173349.

2009. “The U-Shape without Controls: A Response to Glenn.” Social Science \& Medicine 69 (4): 486-88.

Cimentada, J. 2019. "Download Data from the European Social Survey on the Fly R Package Version 1.0. 3."

Easterlin, Richard A. 2001. "Income and Happiness: Towards a Unified Theory." The Economic Journal 111 (473): 465-84. 
Frijters, Paul, and Tony Beatton. 2012. "The Mystery of the U-Shaped Relationship between Happiness and Age." Journal of Economic Behavior \& Organization 82 (2): 525-42.

Fukuda, Kosei. 2013. “A Happiness Study Using Age-Period-Cohort Framework.” Journal of Happiness Studies 14 (1): 135-53.

Galambos, Nancy L, Harvey J Krahn, Matthew D Johnson, and Margie E Lachman. 2020. "The U Shape of Happiness Across the Life Course: Expanding the Discussion." Perspectives on Psychological Science 15 (4): 898-912.

Gerdtham, Ulf-G, and Magnus Johannesson. 2001. "The Relationship between Happiness, Health, and Socio-Economic Factors: Results Based on Swedish Microdata." The Journal of Socio-Economics 30 (6): 553-57.

Glenn, Norval. 2009. "Is the Apparent U-Shape of Well-Being over the Life Course a Result of Inappropriate Use of Control Variables? A Commentary on Blanchflower and Oswald (66: 8, 2008, 1733-1749).” Social Science \& Medicine 69 (4): 481-85.

Hayo, Bernd, and Wolfgang Seifert. 2003. "Subjective Economic Well-Being in Eastern Europe." Journal of Economic Psychology 24 (3): 329-48.

Hsieh, Chang-Ming. 2011. "Money and Happiness: Does Age Make a Difference?” Ageing and Society 31 (8): 1289.

Kassenboehmer, Sonja C, and John P Haisken-DeNew. 2012. "Heresy or Enlightenment? The WellBeing Age U-Shape Effect Is Flat.” Economics Letters 117 (1): 235-38.

Laaksonen, Seppo. 2018. "A Research Note: Happiness by Age Is More Complex than U-Shaped." Journal of Happiness Studies 19 (2): 471-82.

Lee, Sun Youn, and Fumio Ohtake. 2021. "How Conscious Are You of Others? Further Evidence on Relative Income and Happiness." Journal of Happiness Studies.

Lelkes, Orsolya. 2006. “Tasting Freedom: Happiness, Religion and Economic Transition.” Journal of Economic Behavior \& Organization 59 (2): 173-94.

López Ulloa, Beatriz Fabiola, Valerie Møller, and Alfonso Sousa-Poza. 2013. "How Does Subjective Well-Being Evolve with Age? A Literature Review." Journal of Population Ageing 6 (3): 227-46.

Praag, B M S van, P Frijters, and A Ferrer-i-Carbonell. 2003. "The Anatomy of Subjective WellBeing." Journal of Economic Behavior \& Organization 51 (1): 29-49.

Rauch, Jonathan. 2018. The Happiness Curve: Why Life Gets Better after 50. Thomas Dunne Books.

Tsui, Hsiao-Chien. 2014. 'What Affects Happiness: Absolute Income, Relative Income or Expected Income?" Journal of Policy Modeling 36 (6): 994-1007. 
Weiss, Alexander, James E King, Miho Inoue-Murayama, Tetsuro Matsuzawa, and Andrew J Oswald. 2012. "Evidence for a Midlife Crisis in Great Apes Consistent with the U-Shape in Human WellBeing." Proceedings of the National Academy of Sciences 109 (49): 19949 LP - 19952.

Wood, Simon N. 2015. "Package 'Mgcv."”

- 2017. Generalized Additive Models: An Introduction with R. CRC press.

Yang, Yang. 2008. "Social Inequalities in Happiness in the United States, 1972 to 2004: An AgePeriod-Cohort Analysis." American Sociological Review 73 (2): 204-26. 


\section{Supplementary materials}

\section{Decomposition of the effects from the GAM model into main effects and their interaction}

While Figure 5 in the main text shows the predicted surface of happiness in terms of age and income, the figure below decomposes the main and interaction effects that combine to make the predictions. In the representation, the main effect of age is rather wiggly with a dip in middle age and a small recovery after. The main effect of income is positive and slightly curvilinear. The interaction surface is complex: for old people, the effect of income (on top of the main one) is flat, for young people it is negative (again, relative the main effect). For poor people, the effect of age is U-shaped, while for rich people it peaks in mid-life (relative to the main effect of age depicted in the top left panel). In this representation, the interaction effect is in sharper focus, while in Figure 5 in the main text, the predicted values of happiness are easier to trace.
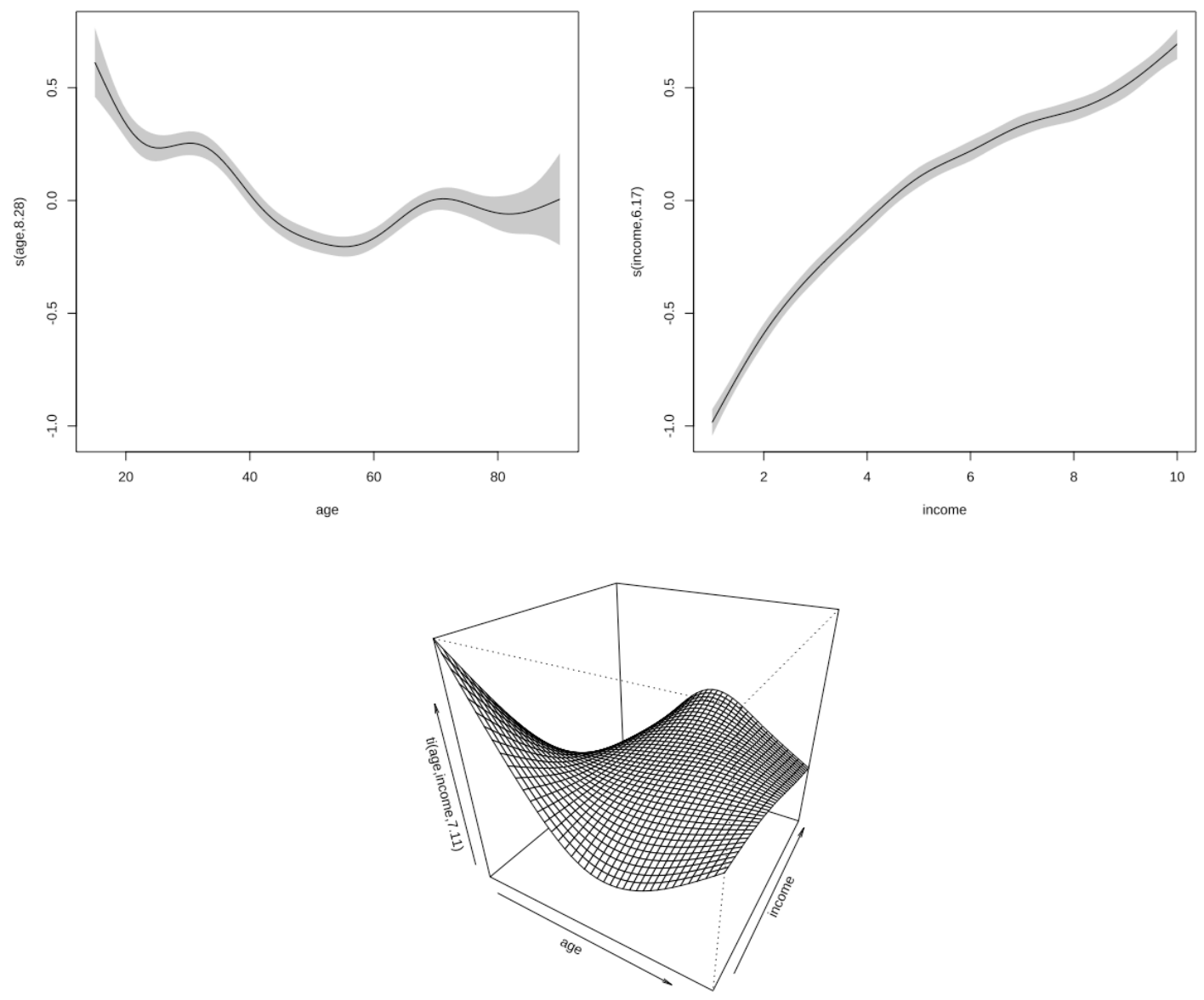

Figure A1. Main and interaction effects of age and income on happiness, based on a GAM model with cubic splines for the main effects and tensor product smooths for the interaction 
Replication with life satisfaction as an outcome variable

The two figures below show the conditional effects of age and income when life satisfaction (also measured on a 0 -to-10 scale) is used as the outcome variable instead of self-reported happiness. The inferences about the impact of age and income remain the same.

\section{Effect of age on life satisfaction for different income deciles}

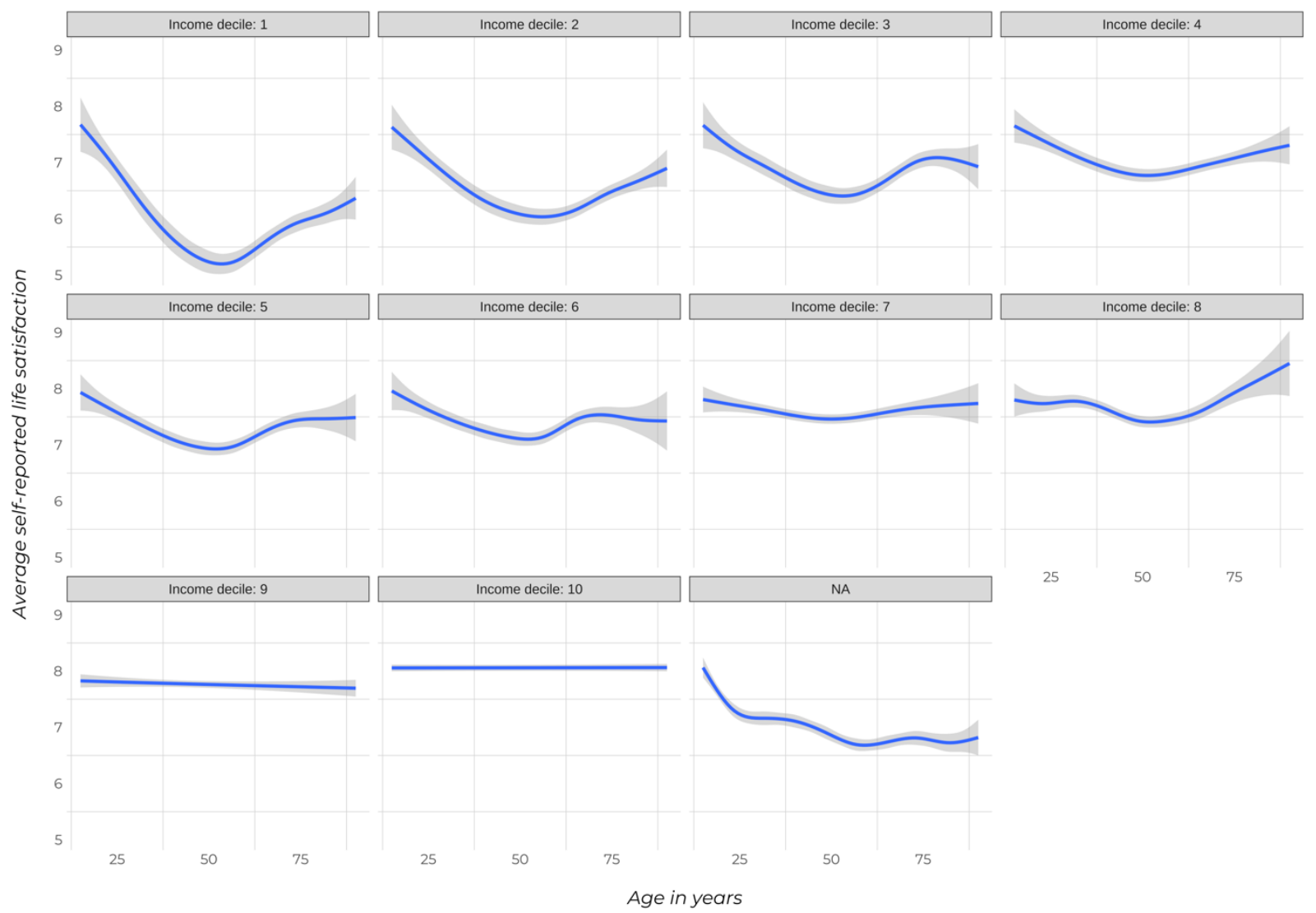

Figure A2. Effect of age on life satisfaction per income decile. 


\section{Effect of income on life satisfaction for different age groups}

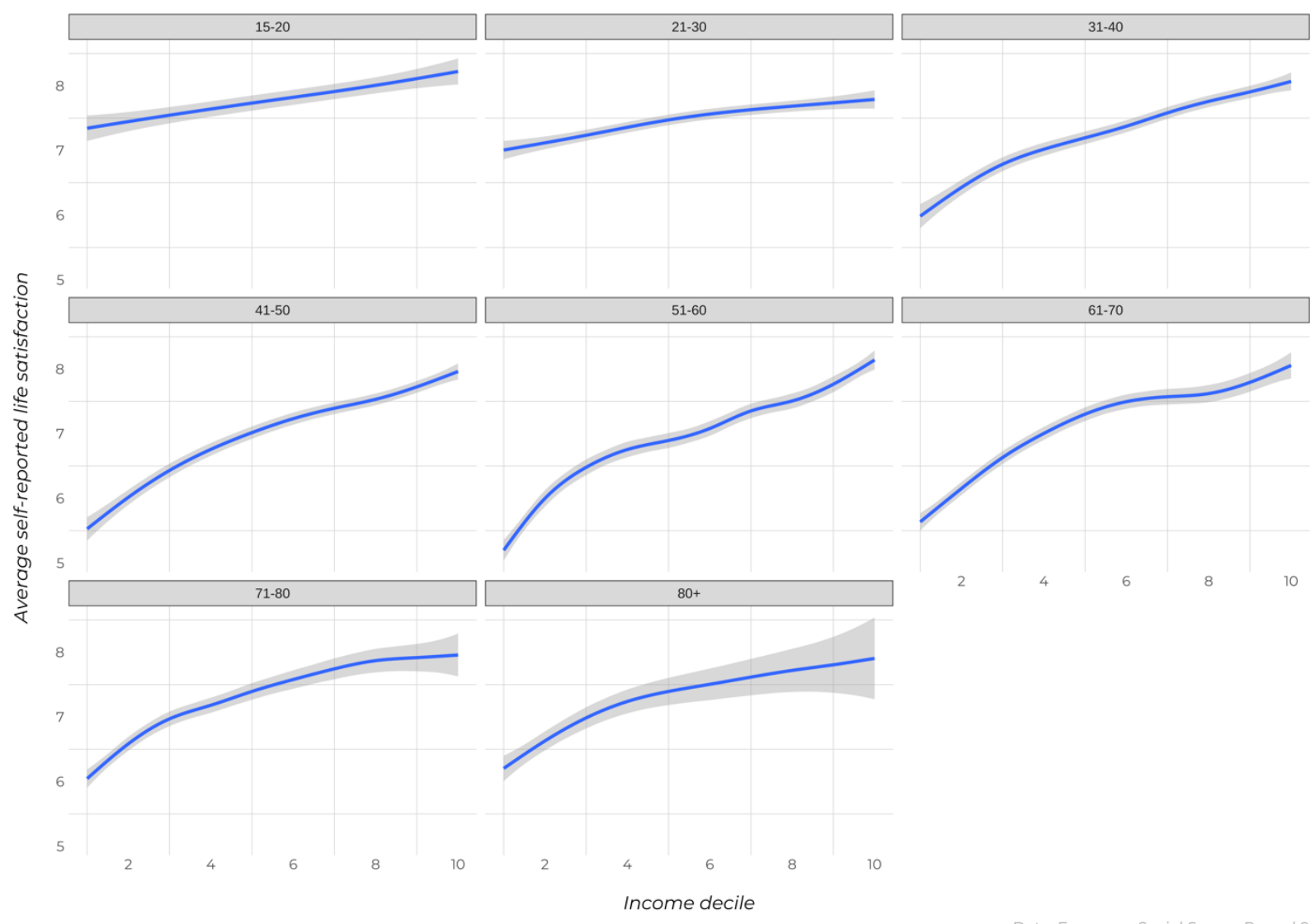

Figure A3. Effect of income decile on life satisfaction per age group. 